\title{
A metáfora, 0 Enem e a democracia
}

\author{
The metaphor, Enem and democracy
}

\author{
Metáfora, Enem y democracia
}

\author{
Diego Bruno Velasco* \\ Ana Angelita Costa Neves da Rocha*
}

\section{Resumo}

O presente trabalho buscou problematizar os sentidos de "democracia" nas edições do Exame Nacional do Ensino Médio (Enem). O objetivo deste trabalho se insere no atual contexto educacional e político do país, em que as garantias dos direitos civis estão ameaçadas e em que consideramos necessário, na posição de docentes da Educação Básica e do Ensino Superior, discutir as disputas pela significação/validação da categoria "democracia" dentro de uma política curricular nacional avaliativa de acesso aos cursos de graduação. A fundamentação teórica se construiu no intenso debate entre a teoria do discurso e a teoria política, a partir de Ernesto Laclau e seus interlocutores. O procedimento metodológico de análise dos itens do Enem observou a estrutura e a proposta de gabarito da questão, indicando como as significações de "democracia" possibilitaram ou não produções de subjetividades ativas. Em linhas gerais, nossas reflexões foram construídas a partir dos discursos produzidos sobre a categoria "democracia" dentro das questões referentes ao tema da Ditadura Civil-Militar (1964-1985) nas edições de 2009 até 2017. A hipótese inicial deste trabalho observou que a democracia é uma potente metáfora para conjugar conteúdos voltados para formação cidadã, ainda pouco explorada pelo exame. Em termos de conclusão, destacamos que o conceito de "democracia" ficou mais restrito a uma concepção tradicional de direito ao voto, mobilizando poucos outros sentidos. Ao mesmo tempo, constatamos que o Enem reforçou a produção de discursos que tenderam a antagonizar o período da Ditadura Civil-Militar com o período da história política do país que se inicia em 1985, apresentando poucos eixos conectivos entre tais momentos históricos.

Palavras-chave: Democracia. Enem. Metáfora. Ditadura Militar.

Recebido em 28/03/2020 - Aprovado em 05/10/2020

http://dx.doi.org/10.5335/rep.v27i3.12385

* Mestrado e doutorado em Educação pela Universidade Federal do Rio de Janeiro. Atua como professor de História no Colégio de Aplicação da UFRJ. Concentra os estudos nas áreas do Currículo e Ensino de História da Educação Básica, analisando livros didáticos, propostas curriculares, provas, entrevistas com profissionais do magistério, dentre outros. Orcid: https://orcid.org/0000-0002-1531-1595. E-mail: profdivelasco97@gmail.com

** Mestrado e doutorado em Educação pela Universidade Federal do Rio de Janeiro; pós-doutorado em Geografia pela Universidade Federal Fluminense; Professora (Adjunto IV) do Departamento de Didática da Faculdade de Educação na Universidade Federal do Rio de Janeiro. Orcid: https://orcid.org/0000-0001-8142-0119. E-mail: geo.ana.angelita@gmail. com 


\section{Abstract}

The present work seeks to problematize the meanings of "democracy" in the editions of the National High School Exam (Enem). The objective of this work is inserted in the current educational and political context of the country, in which the guarantees of civil rights are threatened and in which we consider it necessary, in the position of teachers of Basic Education and Higher Education, to discuss the disputes for the meaning / validation of "democracy" category within a national curriculum policy evaluating access to undergraduate courses. The theoretical foundation was built on the intense debate between the theory of discourse and political theory, from Ernesto Laclau and his interlocutors. The methodological procedure for the analysis of the items of the Enem observed the structure and the proposal for feedback on the question, indicating how the meanings of "democracy" enabled or not enabled the production of active subjectivities. In general, our reflections were built from the speeches produced on the category "democracy" within the issues related to the theme of the Civil-Military Dictatorship (1964-1985) in the 2009 to 2017 editions. The initial hypothesis of this work observed that the Democracy is a powerful metaphor for combining content aimed at citizenship formation, still little explored by the exam. In terms of conclusion, we highlight that the concept of "democracy" was more restricted to a traditional conception of the right to vote, mobilizing few other senses. At the same time, we found that Enem reinforced the production of speeches that tended to antagonize the period of the Civil-Military Dictatorship with the period of the country's political history that began in 1985, presenting few connective axes between such historical moments.

Keywords: Democracy. Enem. Metaphor. Military Dictatorship.

\section{Resumen}

El presente trabajo busca problematizar los significados de "democracia" en las ediciones del Examen Nacional de Bachillerato (Enem). El objetivo de este trabajo se inserta en el contexto educativo y político actual del país, en el que se ven amenazadas las garantías de los derechos civiles y en el que consideramos necesario, como docentes de Educación Básica y Superior, discutir las disputas por el significado/validación de la categoría de "democracia" dentro de una política curricular nacional que evalúa el acceso a los cursos de pregrado. El fundamento teórico se construye sobre el intenso debate entre la teoría del discurso y la teoría política, de Ernesto Laclau y sus interlocutores. El procedimiento metodológico para el análisis de los ítems del Enem observó la estructura y la propuesta de retroalimentación de las preguntas de este examen, indicando cómo los significados de "democracia" posibilitaron o no la producción de subjetividades activas. En general, nuestras reflexiones se construyeron a partir de los discursos producidos sobre la categoría "democracia" dentro de los temas relacionados con el tema de la Dictadura Cívico-Militar (1964-1985) en las ediciones de 2009 a 2017. La hipótesis inicial de este trabajo observó que la democracia es una poderosa metáfora para combinar contenidos destinados a la educación ciudadana, aún poco explorada por el examen. A modo de conclusión, destacamos que el concepto de "democracia" estaba más restringido a una concepción tradicional del derecho al voto, movilizando pocos otros sentidos. Al mismo tiempo, encontramos que el Enem reforzó la producción de discursos que tendieron a antagonizar el período de la Dictadura Civil-Militar con el período de la historia política del país que comenzó en 1985, presentando pocos ejes conectivos entre tales momentos históricos.

Palabras clave: democracia. Enem. Metáfora. Dictadura militar.

\section{Introdução}

As linhas abaixo resultam do exercício de compreensão da teoria do discurso e suas contribuições para investigar como os sentidos de democracia são validados em um Exame aplicado anualmente para milhares de jovens brasileiros egressos 
da Educação Básica. De fato, cabe narrar as nossas aproximações com certas discussões em torno do discurso e suas repercussões para o desenvolvimento do presente estudo, considerando a atual contingência política que ameaça a experiência democrática no país. Logo, com as vias de expressão democráticas interrompidas, é conveniente enfrentar como materiais pedagógicos, nos últimos anos, significaram as garantias dos direitos civis. O recorte do presente estudo é problematizar os sentidos de democracia no Exame Nacional do Ensino Médio (Enem), analisando os itens produzidos entre as edições de 2009 a 2017.

A argumentação é desenvolvida em três seções. Na primeira, intitulada " $\mathrm{Da}$ metáfora da Democracia ao Exame da metáfora”, desenvolvemos uma discussão teórica com autores como Laclau e Mouffe destacando, em termos gerais, as potencialidades de trabalharmos em diálogo com as teorizações do discurso e, de modo mais específico, enfatizando a pertinência de analisarmos a temática da Democracia sob o prisma da categoria "metáfora".

Na segunda seção, denominada "Os sentidos de Democracia em disputa nos itens do Enem: Análise Empírica a partir do diálogo com a temática da Ditadura Militar", mobilizamos discussões pertinentes para a área do Ensino das Ciências Humanas como os debates em torno dos usos públicos da História, do chamado "dever de memória" e do ensino de temas históricos sensíveis, justificando nosso recorte em analisar os itens voltados para o período histórico da chamada "Ditadura Militar" (1964-1985) para refletir sobre os significados de Democracia em disputa.

Por fim, na terceira seção, nomeada "As 'verdades' em disputa sobre a Ditadura Militar e Democracia nos itens do Enem (2009-2017), nossa proposta é desenvolver uma análise empírica dos itens selecionados, apresentando os sentidos de Democracia e Ditadura hegemonizados bem como destacando as relações entre as dimensões temporais do presente e do passado que aparecem em nosso campo discursivo de análise.

Em termos de procedimentos metodológicos para análise dos itens, destacamos que esta investigação foi desenvolvida mediante uma análise discursiva dos itens a partir da postura epistêmica a qual se filia este artigo, a teorização pós-fundacional do discurso. Como este referencial não se encontra preso a uma estratégia metodológica específica, adotamos o procedimento de analisar os discursos produzidos sobre os itens referentes à Ditadura Militar durante as edições de 2009 até 2017.

Como compreendemos o Enem como um espaço curricular que opera com sentidos de "verdades históricas" e "não-verdades históricas" por ser um exame no formato de múltipla escolha e que, por esse motivo, admite apenas uma alternativa considerada certa, a análise discursiva se deu a partir da reflexão em torno das formas que 
apareceu a ideia de "democracia" nas respostas consideradas corretas (nomeadas pelo INEP de gabarito) e naquelas consideradas incorretas (denominadas de distratores).

É neste caminho que destacamos que a presente investigação consistirá em apresentar os discursos majoritariamente mobilizados para a temática selecionada, procurando avaliar as memórias que constantemente são legitimadas e fixadas, as memórias que se negligenciam e marginalizam as narrativas que são validadas porque operam no domínio do verdadeiro.

O pressuposto deste artigo envolve o Enem como política curricular que valida sentidos de democracia na conclusão da Educação Básica. No desenvolvimento das reflexões a partir dos itens do Enem, não por acaso, trabalhamos com a hipótese de que o "dever de memória" é uma operação política, que coordena uma equivalência de disputas sobre os silenciamentos de certos sentidos de democracia, no momento de formação das gerações futuras.

Em função da importância do discurso, não como mero objeto, ou reflexo da linguagem, ao discurso, mas como teoria política, convém discutir os regimes de validação dos saberes a serem ensinados e aprendidos como Democracia, o que impacta numa aprendizagem do campo da significação da cidadania e da justiça social, categorias essas que nos são incontornáveis para a pensar a sociedade brasileira nestas primeiras décadas do século XXI.

\section{Da metáfora da Democracia ao Exame da metáfora}

Neste texto, cabe questionar, sobretudo, se o Enem repercute a distribuição desigual do poder, quando se trata dos conteúdos que envolvem a experiência política. Sem dúvida, esta suspeita é tributária do acúmulo de discussões do campo do currículo, pois, desde meados dos anos 1990, tal campo vem sendo influenciado pelos debates sobre cultura e poder e pelo emprego da categoria discurso.

Em resumo, a triangulação cultura-poder-discurso esteve na esteira da contestação dos modelos explicativos que poderiam ser classificados como essencialistas. A interpretação dos saberes escolares depende de perspectivas que recusam a neutralidade da seleção curricular e que sejam a favor de compreendê-la como processo simbólico profundamente complexo e instável, perspectiva que, por sua vez, favoreceu (como ainda favorece) a adoção do discurso como categoria privilegiada. De modo que, apostamos numa inflexão para a composição teórica que associasse a potência do debate da linguagem com a questão perene no campo do currículo e da didática - isto é, o conhecimento escolar. 
Dessa forma, a discussão de discurso verticaliza seu potencial nas ciências políticas, com o fim de problematizar o "verdadeiro": os regimes que disputam o significado de Democracia no Enem. Diante desse argumento, é possível problematizar se tal assertiva seria uma resposta teórica-metodológica para interpretar o político nos sistemas de validação de saberes (GABRIEL; COSTA, 2010; GABRIEL, 2011, 2017).

No desenho teórico que considera o discurso como constituinte do social, como ontológico do político (LACLAU; MOUFFE, 2005), abre-se uma pista teórica fecunda para uma compreensão de que em textos educacionais, como o Enem, há uma vontade de verdade sobre modelo explicativo que impacta na forma como significamos a "Democracia". Para nossa argumentação, nos parece oportuno o pressuposto de que o discurso é uma categoria ontológica. Por esta razão, assumimos aqui a diferenciação entre teoria do discurso e análise do discurso, formulada por Howarth (2005, p. 10):

Como primeiro uso, o discurso é uma categoria ontológica que especifica o entrelaçamento de palavras e ações nas práticas; a contingência de toda identidade, a primazia da política, e etc. Enquanto o segundo uso do discurso pode ser entendido como um conjunto de representações simbólicas e práticas incorporadas em uma série de textos, discursos e seqüências de significados.

Ao projetar a diferenciação entre teoria do discurso e análise do discurso, Howarth (2005) apresenta não somente a categoria discurso, mas oferece ao leitor que tal distinção está fincada no plano epistemológico. Em suma, o autor reconhece que se trata de distintos terrenos reflexivos para orientar a compreensão da luta por significação. Seguindo essa ordem de ideias, suspeitamos de que há disputas em torno do significar a Democracia no Enem, e, por conseguinte, asseveramos que a teoria do (D)iscurso permite explorar o "controle" em textos curriculares, como a própria manifestação do político e não somente seu reflexo.

Como mencionados acima, os diálogos com os pensamentos de Laclau e Mouffe sobre a experiência democrática estão presentes em artigos e investigações do campo do currículo, como uma estratégia de sinalizar uma leitura mais complexa das relações de poder, especialmente, nas discussões que se preocupam com as políticas de currículo e com as relações políticas na validação do conhecimento escolar (GABRIEL, 2017).

Aqui, nos referenciamos nas expressões "operação metonímica" e "totalização metafórica", desenvolvidas por Laclau no texto intitulado "Política de la retórica" (2000), pois ensaiaremos aqui um exercício de análise do Enem, buscando sublinhar as operações metonímicas que garantem identificações políticas em torno do significado de Democracia. 
Esse exercício, a nosso ver, pode mobilizar interpretações sobre os movimentos paradoxais constituintes de políticas de avaliação, como a do Enem. Em resumo, tendo por base que a operação metonímica é uma operação do particular que se solidariza com outros particulares na ambição de uma significação universal, poderíamos experimentar reflexões sobre os processos de consolidação do Enem, incorporando a ideia da contradição como estruturante da "totalização metafórica".

Como o Enem é uma prova múltipla escolha, onde cada item é composto por cinco alternativas, entendemos que cada questão mobiliza fluxos de sentidos de verdade. Em outras palavras, cada assertiva é plausível e aspira "um valor de verdade", aspira "uma totalização metafórica". Nesse caso, o que está estabelecido provisoriamente na posição de "verdadeiro" corresponde àquela alternativa considerada certa, ou seja, o gabarito segundo a terminologia do Instituto Nacional de Estudos e Pesquisas Educacionais Anísio Teixeira (Inep) enquanto o que se fixa / entende como "não verdadeiro" equivale às respostas consideradas "falsas" ou "erradas" (também conhecidas como distratores, segundo terminologia adotada pelo Inep para este exame).

Em uma política curricular, como o Enem, o considerado "certo" só pode se constituir/afirmar discursivamente a partir da sua cadeia antagônica, que, no caso, é o conjunto de afirmativas incorretas produzidas em cada um de seus itens. Assim sendo, as disputas por significações hegemônicas mobilizam processos epistêmicos de fechamentos/totalizações discursivas, que segundo a terminologia laclauniana, são processos contingentes, visto que cada verdade histórica se constitui de acordo com as demandas de seu tempo presente não podendo ser estabelecida fora dos jogos políticos de fixação de sentidos. Por Tempo Presente, consideramos a relação, instituída dentro de cada sociedade em seu presente vivido, entre campo de experiência (passado) e horizonte de expectativa (futuro) estabelecida por autores como Koselleck (2006).

Nessa perspectiva, dialogamos novamente Howarth (2005, p. 13), quando afirma que:

Como contra abordagens mais tradicionais das ciências sociais, como o positivismo, o realismo, e certas concepções do materialismo, os teóricos do discurso consideram a existência de retórica como um aspecto constitutivo da realidade social, e sua análise teórica e empírica como uma parte essencial para entender e explicar os fenômenos sociais.

A afirmação supracitada sugere que a abordagem dos teóricos do discurso não se limita ao terreno explicativo da análise do texto, como referência retórica, mas também a compõe substantivamente com a finalidade da interpretação do fenôme- 
no social. Para tanto, o autor se dedica a sublinhar a estreita relação entre retórica e análise política, procurando repercutir a metáfora.

Sob a perspectiva da teoria do discurso, não seria injustificado o emprego da retórica para a compreensão do fenômeno político, o que evidencia a potencialidade de incorporar a interpretação da metáfora como sistematização política, considerando a exploração textual. Ainda em "Hegemonia e Estratégia Socialista", Laclau e Mouffe (2005, p. 150) afirmaram que sua (proposta da) concepção da democracia radical depende da centralidade do discurso somado à recusa da dicotomia "pensamento/realidade", voltado principalmente para expansão de categorias para "dar conta das relações sociais".

Para Laclau (2009, p. 86), o jogo metonímico, ou operação metonímica, é condição de possibilidade de produzir um corte antagônico, a fronteira interna que permite "o povo". Com essa argumentação, ele define a hegemonia como totalização metafórica, isto é, as operações metonímicas (entre as unidades políticas chamadas de demanda) vão na direção de uma significação universal, chamada por ele, naquele texto, de "totalização metafórica". Ou seja, antes de ser tendência à totalização metafórica, a hegemonia começa por ser "sempre metonímica" (LACLAU, 2000, p. 74).

O desafio da metáfora é ser uma operação política, que apaga a fronteira da significação ou da fixação de sentidos. De forma que sua compreensão, partindo do terreno da teoria laclauniana, depende do entendimento da lógica hegemônica, como ponto máximo da própria metaforização. O desafio da metáfora também está na análise da superfície textual (no material empírico, eleito neste exercício, como os itens do Enem). O desafio da metáfora consiste, antes de mais nada, em compreendê-la como quadro animado por Laclau para dar inteligibilidade ao movimento da luta hegemônica.

Por essa razão, avaliamos que é oportuno nos dedicarmos a explorar o entendimento e o papel da metáfora nos escritos de Laclau. No ensaio Articulação e os limites da metáfora (2010), a hegemonia é significada como a própria passagem da metonímia para a metáfora, de um ponto de partida "contínuo" para a sua consolidação (ou sedimentação) como analogia. Ou seja, hegemonia pode ser lida com a equivalência convertida em universal.

Howarth (2008, p. 321) interpreta a proposta de prática hegemônica laclauniana a partir do deslocamento do conjunto de reivindicações de um "lugar social a outro", movimento que é iniciado por uma relação de contiguidade em que se aspira à substituição (metaforização). Com a expressão "aspiração", Howarth define o projeto hegemônico, sendo a "estabilização do sistema de sentidos", o ideal de toda metáfora. 
A criação da solidariedade entre demandas (como operação metonímica) deseja envolver o sentido (novo) de totalidade. Nossa suspeita é que há narrativas (ontológicas, como desenvolveremos a frente) que se comportam como tal totalidade metafórica, ao produzir o sentido de democracia, a partir de um "dever de memória" (KALLÁS, 2017). Ao mesmo tempo, tais metáforas podem interditar sentidos outros de democracia que operam no jogo político para formação de gerações futuras.

Não por acaso, temos a aposta que o "dever de memória" é uma operação política, que coordena uma equivalência de disputa sobre os silenciamentos. Em outras palavras, nossa suspeita propõe a problematização do chamado "dever de memória" como prática hegemônica. Com base nesta argumentação, sublinhamos que a definição de Democracia pode ser percebida como operação metonímica que, por vezes, comporta-se como totalidade metafórica.

Na seção a seguir, nos inspiramos nesta interlocução para identificar como os conteúdos do Enem "flutuam" para sistematizar operações que antagonizam a Democracia. Considerando as contingências das políticas educacionais, em que grupos neoconservadores buscam um revisionismo curricular dos conteúdos das ciências humanas, é oportuno exercitar uma chave de interpretação que tencione a relação entre temáticas do conhecimento escolar para validar a democracia como conteúdo do Enem.

\section{Os sentidos de Democracia em disputa nos itens do Enem: uma reflexão sobre a temática da Ditadura Militar em diálogo com a questão do ensino dos temas sensíveis}

Em diálogo com a teoria do discurso, reiteramos que o presente artigo parte do pressuposto de que os processos de hegemonização de sentidos no Enem mobilizam, selecionam e dialogam com os conteúdos escolares. Do mesmo modo, trata-se de uma política curricular que autoriza e, principalmente, hegemoniza certos saberes, certas memórias, determinadas verdades históricas por meio da fixação de alguns discursos em detrimento de outros.

Os sentidos de "verdade" mobilizados na prova do Enem, ao mesmo tempo em que articulam determinadas demandas para formar discursos hegemônicos ou universais, operam também na pauta dos antagonismos, uma vez que o significante "verdade" para se hegemonizar necessita de um "outro", antagônico, aquele situado fora de sua cadeia de equivalência, também denominado de "exterior constitutivo": a "não verdade histórica". 
Assim sendo, as disputas por significações hegemônicas mobilizam processos epistêmicos de totalizações metafóricas, que são processos contingentes, visto que cada verdade histórica se constitui de acordo com as demandas de seu tempo presente. Imbuídos destas reflexões, nossa proposta é produzir uma investigação das complexas relações entre o conhecimento escolar e as noções de "verdade histórica", tendo como principal foco de investigação as disputas discursivas em torno das significações de Democracia no Enem.

Ancorados no referencial teórico aqui privilegiado, entendemos que o processo de produção das narrativas envolve disputas e combates nos diferentes contextos discursivos - história acadêmica e escolar - em que são produzidas. Por conseguinte, as narrativas que se tornam hegemônicas no currículo da Educação Básica assumem tal posição, pois são resultantes dos jogos políticos que deslocam e reafirmam fronteiras em meio ao campo de significação onde estão inscritas.

É neste sentido que advogamos em prol do conceito de "narrativas ontológicas" (GONZÁLEZ, 2013) para pensar as narrativas validadas na esfera do Enem, visto que identificamos um processo de confrontos hegemônicos no interior do conhecimento histórico escolar em torno do que deve ser considerado verdadeiro e importante para um estudante do Ensino Médio saber e quais tantas outras narrativas devem ser silenciadas e/ou negligenciadas.

A dimensão ontológica quando transportada para o campo do Currículo remete à potencialidade de pensar no caráter conflitivo dos discursos acerca dos passados nacionais que devem ou merecem ser visitados pelos alunos. Afinal, Laville (1999) já chamou a atenção ao destacar que a área do ensino de História é um espaço marcado pelas "guerras das narrativas".

Seguindo esta linha, concebemos que da mesma forma que a produção de narrativas não é uma mera operação de sequenciar os fatos cronologicamente, o processo de construção dos itens do Enem é uma operação política: de inclusão/ exclusão das diferentes narrativas produzidas sobre qualquer temática histórica. O caminho que escolhemos para analisar os sentidos de Democracia em disputa e fixados no espaço discursivo do Enem foi através da análise dos itens referentes à temática da Ditadura Militar.

Tal escolha se deve por considerarmos tal conteúdo escolar potente para afirmar/silenciar significados para o conceito de Democracia, visto que as aproximações e distanciamentos entre os contextos políticos de 1964 a 1985 e 1985 a 2017 são pontos importantes para refletirmos sobre os rumos do nosso atual sistema democrático. 
A discussão em torno das verdades que se lutam e se confrontam para validar ganha um ingrediente novo, se pensarmos em nosso contexto contemporâneo marcado pela eclosão de variadas memórias em distintos espaços. É, pois, nesse contexto que assistimos o crescimento dos diferentes usos públicos do conhecimento histórico.

Segundo Kallás (2017, p. 143), a expressão "uso público da História” consiste na veiculação de uma interpretação histórica para um público mais amplo não se resumindo ao público acadêmico, passando por um processo de reconstrução e adaptação historiográfica, de modo a ser lida por mais pessoas: "que se encontra na origem de uma percepção social de profundo desamparo quanto às perspectivas de futuro".

Destaca-se, portanto, que a dimensão dos usos públicos da História acarreta a produção de conflitos de memória, de silenciamentos ou de esclarecimentos referentes a temas pouco debatidos, ao mesmo tempo em que propicia o aparecimento de revisionismos históricos e de transformações na área do Ensino de História.

Escolhemos, portanto, o tema da Ditadura Militar para pensar os sentidos de Democracia mobilizados no Enem, pois é um assunto que apresenta uma forte presença nas diferentes instâncias da sociedade brasileira. Isto significa afirmar que tal passado sofre contínuas revisitações acadêmicas e reelaborações em suas narrativas e, por este motivo, interessam-nos analisá-lo em sua versão escolar.

Os impactos gerados pelo crescimento de narrativas que versam sobre o período da Ditadura se articulam às discussões voltadas ao "dever de memória". Segundo autores como Heymann (2006) e Camargo (2016), este termo aparece no contexto da rememoração, na década de 1970 na Europa, do genocídio sofrido pelos judeus durante a Segunda Guerra mundial. Todavia, foi apenas na década de 1990 que este conceito se tornou relevante no meio acadêmico e político francês.

A expressão "dever de memória" representa "a ideia de que memórias de sofrimento e opressão geram obrigações, por parte do Estado e da sociedade, em relação às comunidades portadoras dessas memórias" (HEYMANN, 2006, p. 4). Ou seja, deste conceito deriva a ideia de que as memórias de dor e sofrimento geram obrigações por parte do Estado e da sociedade para com as vítimas ou grupos de vítimas no sentido de reconhecer as injustiças/violências históricas cometidas.

Reconhecemos que as discussões sobre as disputas de reconhecimento de memórias em diálogo com aquelas voltadas aos diversos usos públicos da História instigam o surgimento de tantas outras memórias e demandas que acabam exercendo influências nos processos de validação dos conteúdos e conhecimentos escolares. 
Há de se destacar ainda que o termo "dever de memória" envolve a crença de que um reconhecimento é devido àqueles que sofreram e que "cada grupo social, em outro tempo vítima, e hoje herdeiro da dor, pode reivindicar a celebração de seus mártires e heróis" (HEYMANN, 2006, p. 7). Como o presente texto caminha em diálogo com as perspectivas do discurso, importa sublinhar que os passados pelos quais se reivindicam lembranças, memórias e até mesmo, um espaço maior nas narrativas produzidas nos currículos não são compreendidos aqui como elementos essencializados e tampouco unívocos.

Concordamos que as demandas por não fazerem esquecer as práticas de torturas adotadas pelos governos militares durante as décadas de 1960, 1970 e 1980 unificaram diferentes movimentos e grupos, mas, ao mesmo tempo, defendemos que o conteúdo daquilo que se narra, o sofrimento de quem se fala, a resistência de quem se clama, são alvos de disputas hegemônicas e contingentes. Até mesmo os status e as hierarquias atribuídas a determinados sofrimentos são frutos de conflitos sobre o que deve ou não adentrar nas diferentes narrativas produzidas, visto que "nem todas as interpretações sobre o passado têm o mesmo valor" (MOTTA, 2013, p. 66).

Concebemos, portanto, que a expressão "dever de memória" - marca ontologicamente o surgimento de lutas por fixações de novas e/ou reatualizadas narrativas históricas no interior das diferentes sociedades e, de modo mais intenso, no Currículo das chamadas Ciências Humanas. Dessa forma, os processos de formação das totalidades metafóricas acabam passando por jogos de linguagens que culminam na desconstrução e reconstrução das narrativas em virtude da eclosão de diferentes vozes e demandas em voga.

As discussões produzidas em torno da Ditadura nos aproximam também com as reflexões voltadas aos "temas/passados sensíveis ou controversos", que se encontram nas discussões referentes ao Currículo de História e de Geografia. Alberti (2014) salienta que os temas do ensino de questões sensíveis ou controversas englobam assuntos diversos como a religião na Irlanda do Norte, o holocausto, o racismo e a escravidão, dentre outros e abrangem a "ideia de que injustiças foram cometidas no passado contra pessoas ou grupos, podendo levar a disparidades entre o que é ensinado nas aulas de história e o que é transmitido nas histórias familiares ou comunitárias" (ALBERTI, 2014, p.2).

Trata-se de um novo terreno de produção e disputas em torno de memórias que acabam impactando naquilo que se ensina na instituição escolar. Para Alberti, o ensino de questões sensíveis e controversas não tem como objetivo chocar os estudantes, mas sim fomentar reflexões sobre eixos temáticos que versem na ênfase 
na diversidade de experiências, problematizando as homogeneizações que tradicionalmente são atribuídas a determinados grupos sociais quando se estuda alguns períodos históricos específicos.

Falaize (2014) destaca que há, pelo menos, vinte anos a questão do ensino de temas sensíveis da História aparece nos debates escolares, públicos e políticos produzidos na França. Em decorrência disso, "as atividades de sala de aula estão sujeitas à interrogação de uma sociedade inteiramente convidada a examinar 0 interior da escola de seus conteúdos de ensino da história, a fim de ver nele ocultamentos, omissões ou amnésias nacionais" (FALAIZE, 2014, p. 227-228).

No entendimento deste autor, o impacto das discussões sobre os passados sensíveis ou controversos marcou uma ruptura com a forma tradicional de narrar a História francesa (pautada nos sentimentos cívicos e patrióticos e na valorização de "heróis nacionais" e "fatos), dessacralizando e questionando as narrativas produzidas. Em seu parecer:

Se olhássemos rapidamente para esta atualidade memorial em plena renovação (BONAFOUX, DE COCK, FALAIZE, 2007), seríamos tentados a ver nela uma verdadeira revolução, ou pelo menos uma ruptura com o passado da disciplina histórica e do seu lugar na escola francesa. (...) é o romance nacional que parece fragilizado, questionado e reavaliado sob uma nova luz. Não há volta às aulas, ou uma atualização memorial ou legislativa, sem que os conteúdos de história abordados na escola, ou mesmo a maneira de contar a história da França, sejam questionados, interrogados e ordenados a dar conta dos traumas do passado nacional (FALAIZE, 2014, p. 228).

O trecho citado faz uma articulação interessante entre a discussão do dever de memória e do ensino de temas sensíveis, mostrando que esta relação gera novas formas de se questionar os passados narrados, através dos conteúdos escolhidos e das tramas construídas, no interior das instituições escolares.

Isso nos permite pensar que o estudo das discussões em torno das relações entre verdade - memória - currículo - conteúdo pode se posicionar na ordem da contingência sem abrir mão de costuras ou suturas, ainda que provisórias, em torno de um sentido de Democracia.

\section{As "verdades" em disputa sobre a Ditadura Militar e Democracia nos itens do} Enem (2009-2017)

Groppo (2015) assinala que as questões de memórias relativas ao período das ditaduras ocupam um lugar importante nas sociedades da América Latina, podendo ser consideradas uma importante demanda social por verdade, justiça e 
reparação. Napolitano (2015), outrossim, assegura que os processos de transição emergentes após o término das ditaduras são acompanhados de operações de "reconstrução da memória", que tem por objetivo principal a superação dos traumas e das fissuras produzidos nas sociedades afetadas por tais tipos de governos.

Em seu entendimento, autênticas "guerras de memória" (NAPOLITANO, 2015, p. 98) são cultivadas na busca pela afirmação das verdades históricas. Cerqueira e Motta (2015), por sua vez, sinalizam que as batalhas de memórias, principalmente no caso de processos traumáticos, decorrem quando diversos grupos disputam o controle das representações do passado em busca de garantir o reconhecimento de suas demandas, sofrimentos e experiências no presente.

Cruz (2015, p. 385) aponta para as disputas pelas memórias hegemônicas, argumentando que "os sentidos que se constroem sobre o passado não se articulam em torno da ausência de objetivos políticos, mas, muito pelo contrário, o que se rememora, silencia ou esquece é em função dos objetivos e projetos do presente".

Seguindo este caminho, entendemos que o espaço discursivo do Enem mobiliza múltiplas demandas de memória e disputas em torno das verdades históricas e, por esse motivo, concordamos com Alice Pereira (2015, p. 349) quando sustenta que "relembrar o passado é instaurá-lo num terreno de disputas entre determinadas versões" marcado pela dialética entre lembrança e esquecimento, considerados não como elementos antagônicos, mas sim como complementares um ao outro.

A partir de uma análise sistematizada sobre os itens referentes ao governo da Ditadura Militar, percebemos que o Enem, de um lado, reforça a ideia do Estado como limitador das liberdades e direitos e, por outro lado, valida as narrativas de resistência e engajamento popular contra o governo que se estabeleceu a partir do golpe de 1964. Constatamos, pois, uma hegemonização das narrativas de "causa e consequência", pois, de um lado, sublinha os discursos sobre o que o Estado fez para controlar e dominar a sociedade e, por outro lado, destaca as narrativas em torno do que ela (sociedade civil) fez para resistir ao autoritarismo em vigência. Percebemos um diálogo pouco desenvolvido entre estas instâncias - Estado e sociedade civil -, uma vez que os discursos se posicionam como se entre a dominação e a resistência não houvesse nenhuma outra alternativa.

Observamos, por conseguinte, o silenciamento das novas dimensões historiográficas sobre as relações entre a sociedade com aquele governo ditatorial. É como que ao afirmar o caráter democrático da sociedade brasileira, o Enem preconiza o seu distanciamento em relação ao governo militar, esquecendo os entrelaçamentos, vínculos e heranças persistentes em nosso país atualmente. 
Nos próximos parágrafos, discutiremos as estratégias discursivas encontradas hegemonicamente nos itens do Enem. Paul Ricoeur (2010) sugere, em suas reflexões sobre as articulações entre o tempo e a narrativa histórica, que existem três possibilidades ou modalidades de visitar o passado: sob o signo do Mesmo, sob o signo do Outro e sob o signo do Análogo.

Segundo este autor, a primeira forma de visitá-lo implica na adoção de estratégias que estimulam eliminar as distâncias temporais. Nesse viés, trata-se de compreender a história como uma "reefetuação do passado" (RICOEUR, 2010, p. 240), pressupondo de toda maneira "uma persistência do passado no presente" e fundindo "as duas temporalidades no presente do historiador" (GABRIEL; COSTA, 2011, p. 136).

A modalidade do "passado sob o signo do Outro", por sua vez, coloca a História na direção do afastamento entre as dimensões do passado e do presente, protagonizando sentidos de "distância temporal" (RICOEUR, 2010, p. 248), em que:

Voltamos assim ao enigma da distância temporal, enigma sobredeterminado pelo afastamento axiológico que nos tornou estrangeiros aos costumes dos tempos passados, a ponto de a alteridade do passado com relação ao presente prevalecer sobre a sobrevivência do passado no presente (RICOEUR, 2010, p. 252).

Em linhas gerais, a segunda modalidade parte de um pressuposto inverso ao identificado na primeira (GABRIEL; COSTA, 2011). Já a modalidade do "passado sob o signo do análogo" associa as esferas do "mesmo e do outro" (RICOEUR, 2010, p. 255). A perspectiva do Análogo, por conseguinte, "conserva em si a força da reefetuação e da colocação a distância” (RICOEUR, 2010, p. 264-265) e opera na tensão entre continuidade e mudança, familiaridade e estranhamento, "possibilitando a produção de identidades em meio a disputas da memória a partir das demandas do presente" (COSTA, 2012, p. 85).

Comparando as diferentes modalidades para pensar essas articulações temporais dentro dos itens referentes à Ditadura Militar, o discurso hegemônico tende a colocar este passado como "exterior constitutivo" do nosso período contemporâneo. Em linhas gerais, a lógica do passado "sob o signo do outro" é reforçada na maior parte das narrativas analisadas.

Os itens relacionados principalmente à década de 1980 sugerem o predomínio de narrativas que opõem, de um lado, a sociedade como um todo e, de outro, o Estado autoritário e repressor. É desta forma que apresentaremos alguns itens relacionados ao movimento das "Diretas Já" e das lutas sindicais ao final do governo militar para enfatizar a dimensão de afastamento temporal entre esses períodos cronológicos. 
A análise dos itens nos possibilita afirmar que o Enem opera em uma lógica que tende a isolar o Estado Ditatorial brasileiro da sociedade brasileira, identificando e ratificando o papel opositor exercido por esta nos chamados "anos de chumbo". A demanda pelo direito ao voto aparece como elemento articulador das lutas pela restituição do regime democrático de governo.

Dentro do bloco de questões associados à temática aqui privilegiada, alguns itens hegemonizam as mobilizações em eventos como as "Diretas Já" como sinônimo da luta pela democracia. Ou seja, o discurso em prol do direito ao voto direto para o Executivo aparece como totalização metafórica em prol da democracia. Cabe destacar que, em sintonia com o que é defendido por Laclau, o universal é aquele discurso particular que se hegemoniza, efetuando uma operação metafórica. Vejamos como isso aparece em alguns itens:

Item 40- Edição 2010B

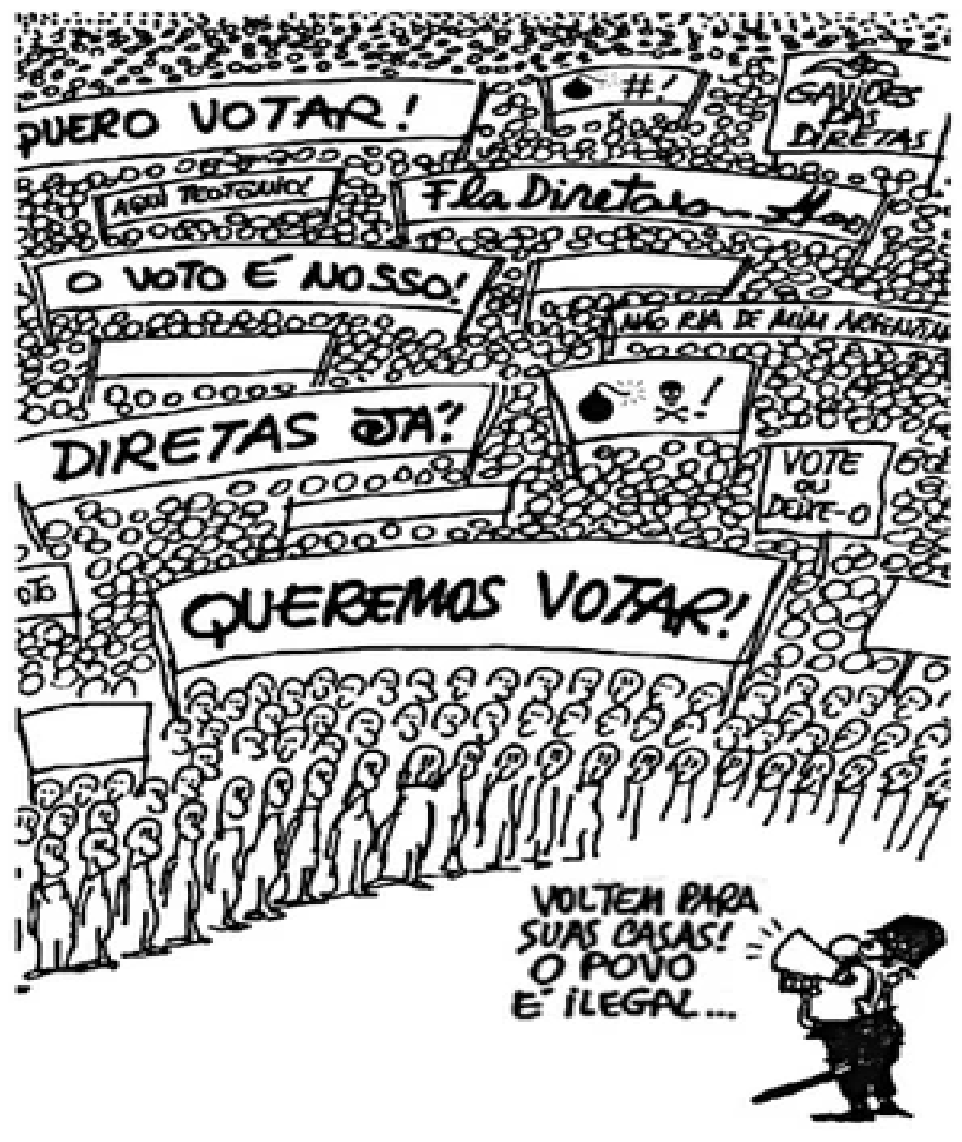

Disponível em: http://pimentacomlimao.files.wordpress.com. Acesso em: 14 abr. 2010 (adaptado). 
A charge remete ao contexto do movimento que ficou conhecido como Diretas Já, ocorrido entre os anos de 1983 e 1984 . O elemento histórico evidenciado na imagem é:

a) a insistência dos grupos políticos de esquerda em realizar atos políticos ilegais e com poucas chances de serem vitoriosos.

b) a mobilização em torno da luta pela democracia frente ao regime militar, cada vez mais desacreditado.

c) o diálogo dos movimentos sociais e dos partidos políticos, então existentes, com os setores do governo interessados em negociar a abertura.

d) a insatisfação popular diante da atuação dos partidos políticos de oposição ao regime militar criados no início dos anos 80 .

e) a capacidade do regime militar em impedir que as manifestações políticas acontecessem (ENEM, 2010).

\section{Item 41- Edição 2010B}

A gente não sabemos escolher presidente A gente não sabemos tomar conta da gente A gente não sabemos nem escovar os dentes Tem gringo pensando que nóis é indigente Inútil A gente somos inútil MOREIRA, R. Inútil, 1983 (fragmento).

O fragmento integra a letra de uma canção gravada em momento de intensa mobilização política. A canção foi censurada por estar associada
A) ao rock nacional, que sofreu limitações desde o início da ditadura militar
B) a uma crítica ao regime ditatorial que, mesmo em sua fase final, impedia a escolha popular do presidente.
C) à falta de conteúdo relevante, pois o Estado buscava, naquele contexto, a conscientização da sociedade por meio da música.
D) à dominação cultural dos Estados Unidos da América sobre a sociedade bra- sileira, que o regime militar pretendia esconder.
E) à alusão à baixa escolaridade e à falta de consciência política do povo brasi- leiro (ENEM, 2010).




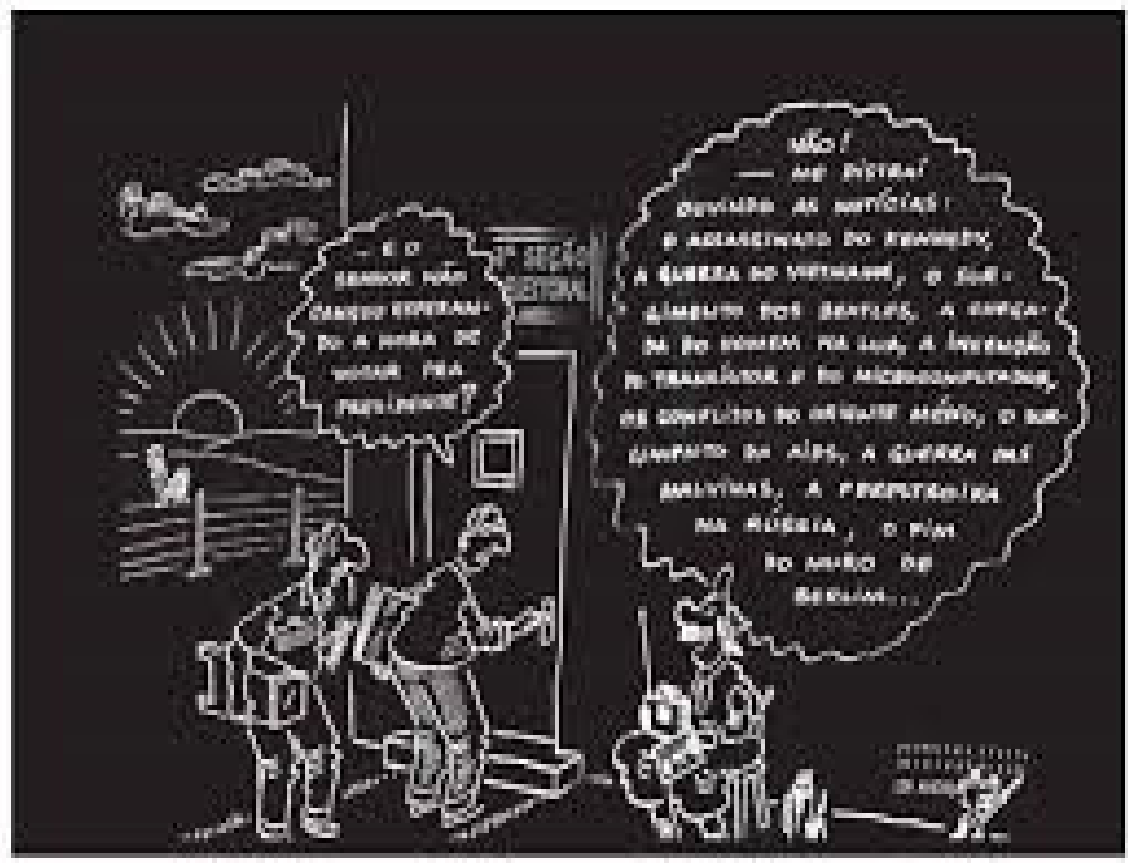

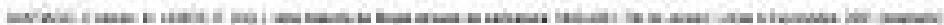

O diálogo que aparece na charge é:

- "E o senhor não cansou esperando a hora de votar pra presidente"?

- "Não! Me distraí ouvindo as notícias: O assassinato do Kennedy, a guerra do Vietnã, o surgimento dos Beatles, a chegada do homem na lua, a invenção do transístor e do microcomputador, os conflitos do Oriente Médio, o surgimento da AIDS, a guerra das Malvinas, a Perestroika na Rússia, o fim do Muro de Berlim..."

O diálogo entre os personagens da charge evidencia, no Brasil, a(s)
A) reinserção do país na economia globalizada.
B) transformações políticas na vigência do Estado Novo.
C) alterações em áreas estratégicas para o desenvolvimento do país.
D) suspensão das eleições legislativas durante o período da Ditadura Militar.
E) volta da democracia após um período sem eleições diretas para o Executivo Federal (ENEM, 2015). 
Os itens de História do Enem priorizam a marca da Democracia como estando intimamente associada às concepções de cidadania e de direito ao voto, reestabelecendo uma articulação bastante clássica no campo do Ensino de História. Logo, as memórias sobre o período em questão imbricam-se com as múltiplas formas de mobilização da população no final do período militar em busca do direito ao voto para presidente.

No item 40/2010B, o movimento das "Diretas Já" é abordado pelo viés da luta pelo voto como representando as variadas demandas pela democracia, reafirmando a ideia de uma "sociedade brasileira" contra a Ditadura e em prol de votação direta. Consideramos que esta imagem é também emblemática daquilo que o Enem pretende significar e fixar como memória a respeito daquele período: a confirmação e fixação de um sentido de sociedade brasileira resistente (esta dimensão da resistência aparece aqui como mobilização pela luta ao direito de votar) ao governo da Ditadura Militar, hegemonizando, por conseguinte, os significados desse significante em disputa pelas diferentes matrizes historiográficas.

Já no item 41/2010B, percebe-se novamente a importância concedida às letras de música como formas de enfrentamento e crítica social / política ao governo dos militares, enfatizando o papel que as produções culturais tiveram naquele período em termos de enfrentamento e resistência. A terceira questão selecionada, item 10/2015B, a seu modo, elenca a quantidade de eventos ocorridos no mundo enquanto perdurava a ditadura militar com o intuito de criticar o período extenso em que a sociedade ficou sem acesso ao direito de votar para o cargo de presidente.

A análise dos itens permite-nos constatar que o Enem ao realizar uma totalização metafórica propõe-se a diferenciar o período da Ditadura e o seu momento posterior, a partir de 1985. Tal operação discursiva produz o sentido de democracia equivalente ao o direito de votar para o cargo de Presidente da República, o que tende a reforçar uma visão simplista e com risco de reforçar uma dicotomização, visto que opera pouco com a possibilidade de produzir interpretações que protagonizem, por exemplo, certos aspectos de continuidades entre estes períodos.

Os itens acima, em suma, dialogam com as perspectivas que destacam as lutas e as conquistas pelo direito ao voto compreendendo-as como narrativas incontornáveis tanto para visualizar a participação da sociedade civil na resistência àquele governo como para demarcar a Ditadura como um período "estranho", "distante" das nossas práticas democráticas atuais. Reforça-se, então, a narrativa da "Ditadura como um passado que não se vive mais nos tempos atuais", como estando nos sentidos de "verdadeiro" dentro do espaço curricular do Enem. 
Nessa percepção, o "povo brasileiro" ou a "sociedade brasileira" resignificados como combativo, resistente e perseguidor de seus direitos políticos, civis e sociais é o que emerge no jogo da memória que se quer fixar na narrativa nacional. Compreendemos, a partir desses vestígios discursivos, que a memória e o regime de verdade que se pretendem legitimar no Enem são os de uma sociedade distanciada do regime político autoritário instaurado no ano de 1964, que se opunha à violência, à repressão e ao terror de Estado. Dito de outra forma, entendemos que essa narrativa se universaliza - é uma totalização metafórica - na ordem discursiva enfocada no presente estudo.

Nessa mesma linha de argumentação, outras formas de resistência ao governo ditatorial aparecem em itens cujas narrativas destacam as greves operárias realizadas no final da década de 1970. Vejamos o exemplo a seguir:

Item 2- Edição 2016 B

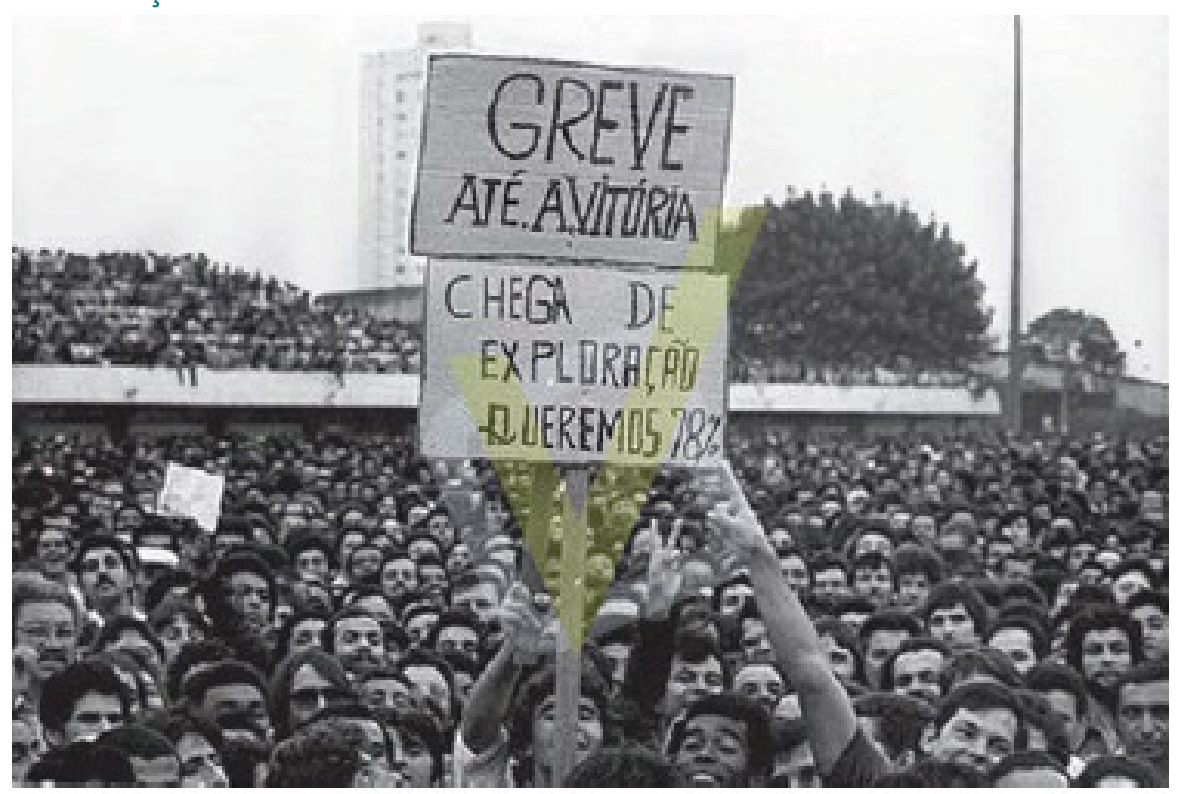

Disponivel em: www1.folha.uol.com_br. Acesso em: 9 nov. 2011.

1) Para além de objetos específicos, muitos movimentos sociais interferem no contexto sociopolítico e ultrapassam dimensões imediatas, como foi o caso das mobilizações operárias, ocorridas em 1979 na cidade de São Paulo. Nesse sentido, ao mesmo tempo em que lutavam por seus direitos, essas mobilizações contribuíram com o(a) 

A) elaboração de novas políticas que garantiram a estabilidade econômica do país.
B) instalação de empresas multinacionais no Brasil.
C) legalização dos sindicatos no Brasil.
D) surgimento das políticas governamentais assistencialistas.
E) processo de redemocratização do Brasil (ENEM, 2016).

A temática da atuação dos movimentos sindicais (principalmente na região do ABCD paulista) nos anos finais do governo da Ditadura é uma temática recorrente no que se refere à participação popular no combate e no enfrentamento aos militares. As narrativas sobre as "Diretas Já" e sobre estas greves, como já destacamos anteriormente, ocupam um papel protagonista nas narrativas que visam legitimar a sociedade brasileira como resistente, principalmente, durante a década de 1980.

O gabarito desse item define que tais mobilizações contribuíram para o processo de redemocratização do Brasil. Portanto, a narrativa mobilizada interliga-se com o discurso que entende as conquistas políticas e sociais por meio também da mobilização dos trabalhadores, conectando a ideia de cidadania com a questão da redemocratização política ao mostrar que este movimento de 1979 ultrapassou "dimensões imediatas" tendo interferido no contexto mais amplo do Brasil.

O item dialoga com a versão escolar da Ditadura quando se pensa no final deste governo. Geralmente, fatos como as greves e o movimento das "Diretas Já" recebem um espaço destacado nos manuais didáticos. Reiteramos que no Enem, quando se pensa nas "narrativas de resistência", a discussão acaba protagonizando principalmente este período final, destacando os acontecimentos das greves e das manifestações entrelaçadas à demanda do movimento das "Diretas Já".

Encerramos a presente seção apresentando pontos de contato entre as análises empíricas com as conclusões de Helenice Rocha sobre a produção referente à temática da Ditadura Militar em livros didáticos. Segundo Helenice Rocha (2017), as narrativas sobre a ditadura nos livros didáticos foram se transformando ao longo da década de 1980. Em geral, enfatiza que os capítulos que versam sobre este assunto tendem a seguir um roteiro que abarca os seguintes temas: a crise do governo João Goulart que teria provocado o golpe de Estado, os diferentes momentos do período ditatorial, destacando a atuação dos presidentes da República naquele período e a posse de Tancredo Neves em 1985, eleito de forma indireta após o movimento popular das "Diretas Já” (ROCHA, 2017, p. 250-251). 
A autora acrescenta que a resistência é tratada nas esferas da produção cultural e da luta armada. Todavia, o que chama atenção em sua produção é o mesmo que encontramos nos itens do Enem: os silenciamentos sobre os consentimentos sociais em relação à implementação e à manutenção do governo militar no período de sua existência, uma vez que nas palavras de Helenice Rocha (2017, p. 257):

O conjunto de narrativas trata do período que se inicia com o golpe de Estado como agenciado principalmente pelas Forças Armadas brasileiras. Poucas coleções mencionam explicitamente a participação da sociedade civil durante a ditadura, atribuindo a determinados representantes da elite uma aliança com os militares para o Golpe.

As reflexões que desenvolvemos no presente artigo nos permite constatar que o Enem, ao operar com uma totalização metafórica, hegemoniza discursos que reforçam os sentidos de Democracia como sendo o governo em que as pessoas têm o direito de votar para eleger seu presidente, apresentando um afastamento entre os eixos temporais de 1964-1985 e de 1985-2017.

Em nosso entendimento, tal esvaziamento de articulações entre tais períodos acaba contribuindo para esvaziar a potencialidade do ensino dos temas históricos sensíveis, visto que reforça a produção de memórias tradicionais sobre o tema e, ao mesmo tempo, silencia a emergência de outras narrativas no espaço discursivo do conhecimento escolar validado na esfera da, até o presente momento, principal política curricular nacional de avaliação da Educação Básica e de ingresso ao Ensino Superior.

\section{Considerações finais}

Formas sedimentadas de "objetividade" constituem o campo do que chamamos de "o social". O momento do antagonismo, onde se faz plenamente visível o caráter indecidível das alternativas e sua resolução através de relações de poder é o que constitui o campo "do político" (LACLAU, 2005, p. 51).

Inspirados, na citação acima, a própria metaforização da Democracia no Enem guarda a natureza da validação dos saberes, isto é, guarda uma pretensão de objetividade. O plano geral do nosso problema é a validade do saber passível de ser ensinado, ou os mais válidos, convertidos em item em escala nacional, na fase final da escolarização obrigatória no Brasil. Logo, a discussão da totalização metafórica como operação hegemônica, reflexão contundente de Laclau, participa diretamente no nosso entendimento como legitimidade dos saberes escolares. Neste artigo, a seleção curricular é a configuração do item. Em outras palavras, o saber válido 
e exigido na prova é, não outra coisa, que as pegadas visíveis de uma totalização metafórica.

Todavia, é importante fazermos um alerta para evitar a produção de generalizações. Em suma, as discussões referentes aos usos públicos da História levam-nos a destacar a importância política e social deste tema e articulá-lo com a discussão das narrativas ontológicas. Portanto, justificamos, então, nossa análise dos itens referentes à ditadura militar no Enem por acreditar que acarreta inúmeras discussões e produções que, de alguma forma, "marcam os estudantes" e o currículo de História em escala nacional.

Nossa suspeita é de que na metaforização do governo ditatorial no Enem, os setores de esquerda permanecem nas narrativas de resistência, porém os conservadores acabam não sendo mais mencionados, pois o foco recai na figura dos presidentes militares, que sintetizam a atuação conservadora no período. Já ao se reportar ao período final da Ditadura, os itens do Enem analisados percebem toda a sociedade como coesa nas manifestações, como ocorre nas narrativas relacionadas ao movimento das "Diretas Já", atribuindo à "sociedade brasileira como um todo a responsabilidade pelo enfraquecimento da ditadura” (ROCHA, 2017, p. 262).

Com efeito, no Enem, a objetividade da Ditadura é definida hegemonicamente como aquele período "outro", "distante" que não apresenta relações com a forma como nossa sociedade se constitui nos dias atuais. Trata-se de um "exterior constitutivo" para aquilo que o exame pretende afirmar como Democracia, como se o período contemporâneo não guardasse nenhum legado daquele momento.

Observando que na atual conjuntura política, há vetores e grupos organizados num revisionismo exaltador do passado da Ditadura Militar, cabe-nos, enquanto educadores, investigarmos os usos públicos da História e suas metáforas. Vale sublinhar as incertezas presentes nas futuras edições do Enem, haja vista que a atual gestão federal se posiciona favoravelmente à censura prévia dos itens, em especial, aqueles que abordam temáticas consideradas desafiadoras à moral da família cristã.

Selecionar os itens de Ciências Humanas do Enem (produzidos entre as edições de 2009 a 2017 e que versavam sobre a chamada Ditadura Militar) e analisá-los com o objetivo de investigar os fluxos de cientificidade e verdade hegemonizados em sua produção a partir das contribuições das teorizações do Currículo e do Discurso foi o caminho, portanto, que trilhamos para analisar os sentidos de Democracia em disputa no espaço curricular do Enem. 


\section{Referências}

ALBERTI, V. O professor de história e o ensino de questões sensíveis e controversas. Palestra proferida no IV Colóquio Nacional História Cultural e Sensibilidades, realizado no Centro de Ensino Superior do Seridó (Ceres) da Universidade Federal do Rio Grande do Norte (UFRN), em Caicó (RN), de 17 a 21 de novembro de 2014.

CAMARGO, A. L. O dever de memória do estado no processo de justiça de transição no Brasil. Idéias - Rev. Inst. Filos. Ciênc. Hum. Unicamp, Campinas, v. 7, n. 1, p. 249-270, jan/jul. 2016.

CERQUEIRA, A. S. L. da G.; MOTTA, R. P. S. Memória e esquecimento: o regime militar segundo pesquisas de opinião. In: QUADRAT, S. V.; ROLLEMBERG, D. (org.). História e Memória das ditaduras do século XX. Rio de Janeiro: Editora FGV, 2015. V. 1.

COSTA, W. da. Currículo e produção da diferença: "negro" e "não-negro" na sala de aula de história. Tese (Doutorado em Educação) - Faculdade de Educação, Universidade Federal do Rio de Janeiro, 2012.

CRUZ, M. A. A Igreja Católica, a ditadura e os dilemas da memória no Chile. In: QUADRAT, S. V.; ROLLEMBERG, D. (org.). História e Memória das ditaduras do século XX. Rio de Janeiro: Editora FGV, 2015. v. 1.

FALAIZE, B. O ensino de temas controversos na escola francesa: os novos fundamentos da história escolar na França? Revista Tempo e Argumento, Florianópolis, v. 6, n. 11, p. 224-253, jan./ abr. 2014.

GABRIEL, C. T. Conteúdo-rastro: um lance no jogo da linguagem do campo curricular. Currículo Sem Fronteiras, v. 17, p. 515-539, 2017.

GABRIEL, C. T.; COSTA, W. Currículo de História, Política da Diferença e Hegemonia: diálogos possíveis. Educação e Realidade, v. 36, p. 127-146, 2011.

GABRIEL, C. T.; COSTA, W. Que "negro" é esse que se narra nos Currículos de História?. Teias, Rio de Janeiro, v. 11, p. 1-20, 2010.

GONZÁLEZ, F. C. A nação como relato: a estrutura narrativa da imaginação nacional. Revista Brasileira de Ciências Sociais, São Paulo, v. 28, n. 82, p. 107-118, jun. 2013.

GROPPO, B. O mito da sociedade como vítima: as sociedades pós-ditatoriais em face de seu passado na Europa e na América Latina. In: QUADRAT, S. V.; ROLLEMBERG, D. (org.). História e Memória das ditaduras do século XX. Rio de Janeiro: Editora FGV, 2015. v. 1.

HEYMANN, L. O “devoir de mémoire” na França contemporânea: entre a memória, história, legislação e direitos. In: SEMINÁRIO PRONEX “CIDADANIA E DIREITO”, 3, Rio de Janeiro. Anais [...]. Rio de janeiro: CPDOC, 2006. p. 1-26.

HOWARTH, D. Hegemonía, subjetividad política y democracia radical. In: CRITCHELY, S.; MARCHART, O. (org.). Laclau aproximaciones criticas a su obra. Fondo de cultura econômica, BsAs, 2008. p. 317-343. 
HOWARTH, D. Metaphor, Catachresis and Equivalence: The Rhetoric of Freedom to fly in the struggle over aviation policy in the United Kingdom. In: ECPR JOINT SESSION OF WORSHOPS. Granada, April, 2005. Disponível em: eis.bris.ac.uk/ potfc/Granada/. Acesso: out. 2012.

KALLÁS, A. L. Usos públicos da história: origens do debate e desdobramentos no ensino de história. Revista História Hoje, São Paulo, v. 6, n. 12, p. 130-157, 2017.

LACLAU, E. Razón Populista. FONDO DE CULTURA ECONÓMICA, Buenos Aires, 2009.

LACLAU, E.; MOUFFE, C. Hegemonia y estratégia socialista - hacia uma radicalización de La democarcia. Buenos Aires: Fondo de Cultura Económica, 2005.

LACLAU, E. Nuevas reflexiones sobre la revolución de nuestro tiempo. Buenos Aires: Nueva Visión, 2005.

LACLAU, E. Misticismo, retorica y política. Buenos Aires: Fondo de Cultura Económica, 2000.

LAVILLE, C. A guerra das narrativas: debates e ilusões em torno do ensino de História. Revista Brasileira de História, São Paulo, v. 19, n. 38, p. 125-138, 1999.

MOTTA, R. P. S. História, Memória e as disputas pela representação do passado recente. Patrimônio e Memória, São Paulo, Unesp, v. 9, n. 1, p. 56-70, jan./jun. 2013.

NAPOLITANO, M. Os historiadores na "batalha da memória": resistência e transição democrática no Brasil. In: QUADRAT, S. V.; ROLLEMBERG, D. (org.). História e Memória das ditaduras do século $X X$. Rio de Janeiro: Editora FGV, 2015. v. 1.

PEREIRA, A. A. O silêncio dos inocentes: construções memorialísticas de Israel Klabin e Rubem Fonseca sobre um passado que insiste em não morrer. In: QUADRAT, S. V.; ROLLEMBERG, D. (org.). História e Memória das ditaduras do século XX. Rio de Janeiro: Editora FGV, 2015. V. 1.

RICOEUR, P. Tempo e Narrativa: a intriga e a narrativa histórica. Volume 3. São Paulo: WMF Martins Fontes, 2010.

ROCHA, H. A ditadura militar nas narrativas didáticas. In: ROCHA, H.; REZNIK, L.; MAGALHÃES, M. S. (org.). Livros didáticos de história: entre políticas e narrativas. Rio de Janeiro: FGV Editora, 2017. 